\title{
MARKETING DIGITAL NA CAPTAÇÃO E FIDELIZAÇÃO DE CLIENTES: A VISÃO DE ALUNOS DO CURSO DE ADMINISTRAÇÃO DE UMA INSTITUIÇÃO DE ENSINO SUPERIOR
}

\author{
https://dx.doi.org/10.48097/2674-8673.2021n5p14
}

\author{
Arandi Maciel Campelo ${ }^{1}$ \\ Eryk Marcelo Portela Silva ${ }^{2}$ \\ Eslla Mirely Oliveira Silva ${ }^{3}$ \\ Robson Domingos de Souza ${ }^{4}$
}

\section{RESUMO}

Este artigo foi realizado com base em pesquisas bibliográficas e de campo, em torno da utilização de estratégias de marketing digital na captação e fidelização de clientes, e teve como campo investigativo alunos do curso de administração da Faculdade Metropolitana da Grande Recife - FMGR. O estudo foi centrado em demonstrar as estratégias de marketing digitais que são praticadas pela empresa, à ótica de seus alunos, no ambiente online que funciona como o caminho ideal para o alcance dos objetivos de cada marca, cada instituição, existentes em diversas redes sociais. A investigação bibliográfica foi desenvolvida a partir de estudos de livros, pesquisas em sites e teve, como principal fonte, as bases conceituais de Kotler $(2010 ; 2017)$, dentre outros autores. A pesquisa de campo, realizada em 2020, com aplicação de questionários, através da ferramenta do Google Forms, revelou que qualquer estratégia ou ação que vise captar e fidelizar clientes deve preceder de objetivos de marketing bem definidos, e seu processo de criação e veiculação nas mídias sociais precisam, necessariamente, estar relacionados com o que se espera alcançar de modo alinhado com os propósitos da instituição em estudo.

Palavras-chave: Marketing digital. Captação e fidelização de clientes. Redes sociais.

Data de submissão: $27 / 11 / 2020$

Data de aprovação: 22/02/2021

\section{ABSTRACT}

This article was carried out based on bibliographic and field research, around the use of digital marketing strategies in attracting and retaining customers and had as investigative field

1 Orientador. Doutor em Educação - Universidade Federal de Pernambuco; Administrador - Universidade de Pernambuco - FCAP/UPE; Mestre em Planificación y Gestion Organizacional - Universidad Autonoma de Madrid / Espanha; Mestre em Dirección y Organización de Hospitales y Servicios de Salud - Universidad Politécnica de Valencia / Espanha; Especialista em Marketing - FCAP/UPE; Consultor em Sistemas Organizacionais, desde 1984; Professor e Diretor Acadêmico da Faculdade Metropolitana da Grande Recife.

E-mail: arandi.campelo@globo.com

2 Aluno de Administração / Faculdade Metropolitana da Grande Recife.

E-mail: erykmarcelo-portela@hotmail.com

3 Aluno de Administração / Faculdade Metropolitana da Grande Recife.

E-mail: mirellymendess@gmail.com

4 Aluno de Administração / Faculdade Metropolitana da Grande Recife.

E-mail: robsonadm28souza@gmail.com 
students from the administration course at Faculdade Metropolitana da Grande Recife FMGR. The study was centered on demonstrating the digital marketing strategies that are practiced by the company, from the perspective of its students, in the online environment that works as the ideal way to reach the goals of each brand, each institution, existing in different social networks. The bibliographic investigation was developed from book studies, website searches and had, as main source, the conceptual bases of Kotler $(2010 ; 2017)$, among other authors. The field research, carried out in 2020, with the application of questionnaires, using the Google Forms tool, revealed that any strategy or action aimed at attracting and retaining customers must precede well-defined marketing objectives and their process of creation and placement in Social Media must necessarily be related to what is expected to be achieved in line with the purposes of the institution under study.

Keywords: Digital marketing. Attracting and retaining customers. Social networks.

\section{INTRODUÇÃO}

$\mathrm{O}$ artigo aborda fatores do marketing digital, imprescindíveis às organizações, como meio de lidar com as dificuldades e a falta de informação que, além de comprometer a comunicação com seus consumidores, dificultam a captação de novos clientes e, principalmente, sua fidelização.

$\mathrm{Na}$ sociedade moderna a competitividade interfere de modo significativo no contexto das organizações, uma vez que há uma quantidade enorme de empresas, além de uma grande variedade de produtos e serviços oferecidos. Neste cenário, o conhecimento e o capital intelectual são bens bastante valorizados pelas instituições. Portanto, as empresas estão usando estratégias para adquirir melhor conhecimento acerca do ambiente interno/externo e de seus concorrentes, visando oferecer produtos e serviços mais atrativos.

\section{REFERENCIAL TEÓRICO}

Como referencial teórico baseamos nossa pesquisa em temas focados na força do marketing digital, na captação e fidelização de clientes, que subsidiaram a construção do trabalho de campo, realizada com alunos do curso de administração da FMGR, com o propósito de apresentarem sua visão sobre as estratégias de marketing digital aplicadas pela instituição investigada, pois "na internet, a interação é uma vida de mão dupla. Os clientes têm mais voz e podem multiplicar sua fala rapidamente, não são apenas receptores, são também emissores de mensagens". (FARIAS et al, 2015, p. 19).

A investigação bibliográfica foi desenvolvida a partir de estudos de livros, artigos e pesquisas em sites e teve, como principal fonte, as bases conceituais de Kotler et al (2010; 2017), dentre outros autores como Farias et al (2015; 2016) e Lima (2012). 


\section{Marketing digital}

Antes de demonstrar a finalidade e aplicabilidade das redes sociais nas relações de vendas, é importante compreender o que vem a ser o marketing digital. Consiste em ações de comunicação que as organizações podem utilizar, por meio da internet, da telefonia celular e outros meios digitais, com o propósito de divulgar e comercializar seus produtos e serviços, conquistando novos clientes e melhorando sua rede de relacionamentos.

O marketing digital é uma estratégia de vendas, no mundo das redes sociais, proporcionando relações com clientes, através da comunicação, que pode proporcionar amplas oportunidades de negócios, lançamento de novos produtos no mercado etc. Com a evolução da tecnologia essas possibilidades são, cada vez mais, ampliadas, pois a onda tecnológica da atualidade permite a conectividade e a interatividade entre indivíduos e grupos; indivíduos e organizações; indivíduos, organizações e mercado. (KOTLER et al, 2010, p.7).

Além de impulsionar produtos relacionados aos clientes, o marketing digital atende às necessidades dos mesmos de maneira rápida e confortável, ganhando tempo no mercado e melhorando o desempenho das vendas. É fato que a sociedade, de um modo geral, está vinculada e dependente da internet e das redes sociais, por isso o marketing digital facilita o alcance e a visualização de marcas e produtos, algo extremamente desejável e necessário a qualquer segmento organizacional.

Outro aspecto fundamental é a oportunidade que se tem em conhecer e segmentar o mercado consumidor, pois o "marketing precisa segmentar o mercado e desenvolver um produto superior para um mercado-alvo especifico. A regra de ouro, segundo a qual cliente é rei, funciona bem para a maior parte das empresas." (KOTLER et al, 2010, p. 4). No mercado competitivo o marketing digital está diretamente relacionado a ganho de espaço nos negócios, proporcionando a apresentação do melhor produto, preço, a melhor promoção, bem como a forma mais eficiente de levar o produto ao consumidor, gerando sensação de segurança e satisfação para quem compra e para quem vende.

Com boas informações, pode-se chegar ao público alvo com maior rapidez e eficiência através das redes sociais, facilitando a captação, fidelização e motivação de clientes.

Atualmente existem diversas técnicas, ferramentas e meios que facilitam a atração da presença online das pessoas, para quem divulga produtos e serviços através de redes sociais, do próprio portal oficial da organização. No entanto, para que isso seja realidade, é necessária a presença de um profissional de marketing e um profissional de redes sociais que unam esforços não apenas de curto prazo, imediatista, mas, principalmente, de longo prazo, ou seja, 
“O futuro do marketing será moldado em parte pelos eventos atuais e, em parte, pelas forças no longo prazo.” (KOTLER et al, 2010, p. 33).

\section{Relacionamento com clientes}

Para ter um bom relacionamento com clientes é preciso compreender a necessidade de construir e gerenciar relacionamentos duradouros com os mesmos, que pode resultar em lucratividade a curto, médio e longo prazos. Há várias ferramentas capazes de mensurar a lucratividade, oriunda das relações com clientes como, por exemplo, o Customer Equity, que consiste em capturar valores de todos os clientes, ao longo do tempo, a partir de produtos que possam representar valores de qualidade, reconhecidos pelos clientes. Nessa perspectiva, é preciso repensar seus produtos e serviços e em que neles pode-se agregar valor. Desse modo, poderá captar novos clientes, atraídos por essas transformações, pois as organizações devem focar na "[...] quantidade de pessoas que jamais teriam acesso a um determinado produto e que, a partir dessa transformação, podem conhecê-lo e comprá-lo.” (FARIAS et al, 2015, p. 241).

Com foco no Customer Equity, é possível ter uma margem de lucratividade e fidelidade de clientes e o marketing digital, nesse sentido, revela-se como poderosa ferramenta para que essas ações cheguem aos ouvidos de seus clientes.

\section{Como lidar com a concorrência nas redes sociais}

A cada dia a concorrência se torna mais acirrada e competitiva, proporcionando, por um lado, elevado grau de preocupação às organizações, mas por outro lado, abrindo um vasto e amplo campo de oportunidades de melhoria dos produtos e serviços ofertados no mercado. Para que isso ocorra é necessário que as estratégias sejam cada vez mais inovadoras, de modo que possam ser financeiramente viáveis, algo que o marketing digital pode proporcionar, a partir das oportunidades geradas através das redes sociais. Trata-se de investir para atrair a atenção do mercado, do cliente, pois "[...] a percepção do cliente a respeito da empresa, que gera um lucro não contábil significativo, precede o impacto financeiro.” E tal impacto, obviamente, é impulsionado pela atração e fidelização de novos clientes. (FARIAS et al, 2015, p. 247).

As redes sociais dão muitas oportunidades de multiplicar vendas e ter autoconhecimento de sua marca, como os canais do Youtube, Facebook, Instagram, Linkedin, blogs, entre outros, tornando as organizações mais preparadas para o enfrentamento com seus concorrentes. Um planejamento bem estruturado do marketing digital veiculado nas redes 
sociais pode transformar seus clientes em potenciais vendedores a custo zero, uma vez que "o papel dos consumidores não está limitado a promover as marcas; estende-se também a vendêlas." (KOTLER et al, 2010, p. 109).

\section{Captação e fidelização de clientes}

A fidelização de clientes é uma tarefa muito difícil para as organizações, independentemente se ela é de bens e/ou serviços. O diferencial está na sua capacidade de agir de forma proativa junto aos seus clientes. Atitudes simples e verdadeiramente focadas nas necessidades atuais e potenciais de clientes podem fazer muita diferença nas ações de captação e fidelização. Nesse sentido, é fundamental conhecer seu público e identificar suas necessidades e desejos em relação ao que é ofertado no mercado.

Para que isso aconteça é necessário estruturar cadastros com dados dos clientes que facilitem sua identificação - não só dados de documentação e identificação, mas dados adicionais como hobbies, práticas de esportes, clubes de futebol etc.

De acordo com Lima (2012), a organização não dever olhar para o produto a ser ofertado ao cliente, mas para as necessidades do cliente, de modo a oferecer soluções, preços, e uma boa relação e não, simplesmente, um produto a ser comprado e consumido. Nesse sentido cabe afirmar que:

É evidente que não se deve fazer tudo o que o cliente quer sem que haja uma margem de contribuição viável na negociação. Mas desconsiderar suas necessidades e impor-lhe produtos-padrão parece não ser mais suficiente atualmente. (LIMA, 2012, p. 110).

Com o advento da internet e das mídias sociais, as organizações criam estratégias para divulgação no mundo digital, cada dia mais utilizadas, impulsionando as atividades do ecommerce, ou seja, "Hoje vivemos em um mundo totalmente novo. A estrutura de poder está passando por mudanças drásticas. A internet, que trouxe conectividade e transparência às nossas vidas, tem sido em grande parte responsável por essas transformações." (KOTLER et al, 2017, p. 17).

A utilização de estratégias alicerçadas no marketing digital melhora consideravelmente a comunicação entre organizações e clientes, pois, atualmente, é possível se fazer quase tudo sem ter que sair de casa. Criar uma relação com os clientes terá sempre como consequências positivas a atração e fidelização dos mesmos. Segundo Gummesson (2010), trata-se de uma função organizacional, sendo "um conjunto de processo para a criação, comunicação e entrega de valores aos clientes, bem como para a administração de relacionamentos com os 
clientes de modo que beneficie a organização e seus stakeholders.” (GUMMESSON, 2010, p. 30). Interagindo com seus clientes, através das redes sociais, as organizações elevam sua visibilidade, atraindo e fidelizando clientes potenciais.

\section{Inteligência competitiva do marketing digital}

A inteligência competitiva, proporcionada pelo marketing digital, é um modelo que capta e organiza muitas informações relevantes sobre os concorrentes; identifica comportamentos dos clientes; e facilita a compreensão de como o mercado está funcionando, as tendências e cenários para o futuro, melhorando os processos de tomada de decisões a curto, médio e longo prazos.

As organizações precisam conhecer, cada vez mais, quem são seus clientes, seus hábitos de consumo, hobbies etc. O uso desses dados, facilmente rastreados pela inteligência competitiva, pode agregar valor aos produtos e serviços ofertados pelas organizações, ampliando sua capacidade competitiva.

Em um cenário de alta competitividade que permeia a realidade contemporânea, a inteligência competitiva proporciona inúmeras ferramentas que possibilitam a coleta de dados, transformando-os em informações úteis. As redes sociais, por sua vez, tendem a ser um campo cada vez mais crescente nesse sentido. As organizações, aproveitando esse momento, utilizam as redes sociais para montarem suas estratégias competitivas, passando a ser uma das ferramentas mais utilizadas na web. As empresas estão usando-as para conhecer melhor seus clientes e concorrentes. Desta forma, as comunidades virtuais e/ou redes sociais se configuram como importantes fontes e canais de informações que podem auxiliar significativamente na geração do processo de inteligência competitiva organizacional.

\section{A força das redes sociais na captação e fidelização de clientes}

Atualmente existe a necessidade de adaptação à constante evolução da cultura tecnológica e das redes sociais. Nesse contexto, a influência da popularidade, reputação e visibilidade exercida pelas redes sociais criam relacionamentos não só entre as pessoas, mas entre clientes e organizações também. É necessário ter atenção a esse fenômeno que, a cada dia, se inova e renova o mercado do marketing digital. Na realidade, "a serviço da economia de mercado, que domina os meios de comunicação de massa, a informação frequentemente se transformar em publicidade comercial e em propaganda politica.” (GÓMEZ, 2015, p. 18).

O marketing digital não é apenas parte, mas uma das principais partes da comunicação que vem se desenvolvendo e promovendo transformações no modo como as relações entre 
pessoas e organizações estão se estabelecendo. A mídia social, que se utiliza das redes sociais, consiste em um conjunto de aplicações baseadas na internet, construídos sob fortes influências ideológicas, típicas dos diversos grupos sociais que se utilizam desses meios de comunicação global. Logo, é preciso investir em redes sociais, fazer anúncios e propagandas, publicação, criar grupos, investir em pessoas com visibilidade, ligadas à mídia social, pois, não por acaso, "o movimento social é caracterizado pela união de pessoas em torno de um objetivo comum, que compartilham valores políticos e culturais, criando, assim, uma identidade comum ao movimento." (SANTOS, 2018, p. 14).

\section{Gestão do relacionamento com clientes}

$\mathrm{Na}$ era da comunicação, investir na gestão de relacionamento com o cliente é uma das melhores táticas para se diferenciar no mercado. Visando um bom relacionamento com os clientes e suas necessidades, é preciso identificá-los não apenas como clientes, mas como indivíduos, e fazê-los se sentir como parte integrante da organização, caracterizando-os por suas características, valores, peculiaridades e, a partir daí, personalizar a oferta em função do perfil de cada grupo de clientes.

Essa é uma forma bastante eficiente de promover atrativos com versatilidade e visibilidade para os clientes. Tais estratégias devem ser implementadas através de campanhas promocionais e sazonais, através das redes sociais, se configurando como um considerável diferencial na construção e segurança das relações entre organizações e clientes, numa projeção fiel e duradoura, com muita rapidez, o que pode ser plenamente viabilizado através da tecnologia, pois como já afirmava Gómez, “[...] a internet pode estar antecipando uma nova forma de pensar baseada mais nos processos do que nos produtos, na necessidade imperativa de sintetizar a vasta e diversificada morfologia atual da informação." (GÓMEZ, 2015, p. 25).

\section{METODOLOGIA}

O objeto de estudo deste projeto consistiu no marketing digital aplicado ao relacionamento de uma instituição de ensino superior com seus alunos. Como objetivo geral, buscou-se verificar como se dá a comunicação da instituição com os alunos, através de redes sociais como o Instagram, Facebook e Whatsapp. Especificamente, procurou-se:

a) Identificar as principais dificuldades que os alunos têm em se comu nicar com a instituição, através das redes sociais; 
b) Obter sugestões dos alunos para aprimorar a forma de comunicação da instituição com os mesmos, através das redes sociais.

O tipo de instrumento utilizado na pesquisa de campo foi o questionário semiaberto com perguntas objetivas e subjetivas. A amostra foi de 30 estudantes do curso de administração, cujo universo contempla 200 alunos regulamente matriculados no semestre letivo em que ocorreu a pesquisa (2020.1). Os critérios para definição dessa amostra foram:
a) Alunos do curso de Administração;
b) Cursando do $1^{\circ}$ ao $4^{\circ}$ período;
c) Com idade entre 20 a 50 anos;
d) Regularmente matriculados nos turnos da manhã e noite.

\section{DESENVOLVIMENTO DA PESQUISA DE CAMPO}

A pesquisa de campo, que subsidiou este artigo, foi aplicada a alunos do curso de Administração da Faculdade Metropolitana da grande Recife, através do Google Forms. Das doze questões indagadas, oito merecem destaque pela relevância das respostas, ao serem analisadas à luz do referencial teórico.

\section{Gráfico 1 - O que você acha da divulgação de cursos e eventos da Faculdade Metropolitana?}
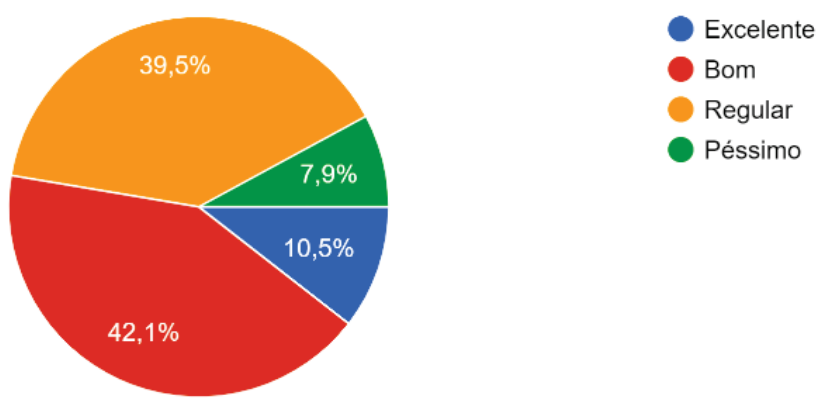

Dentre os participantes da pesquisa, $52,6 \%$ classificaram entre excelente e bom o trabalho de divulgação que o campo investigativo deste artigo vem realizando em termos de divulgação de seus eventos. Uma perspectiva que vai de encontro com a fala de Kotler et al (2010, p. 33) ao afirmar que “o futuro do marketing será moldado em parte pelos eventos atuais e, em parte, pelas forças no longo prazo", algo que é fortemente proporcionado através da divulgação de eventos, nas redes sociais, pela instituição investigada. 
Gráfico 2 - Você acha que a Faculdade deveria investir mais em propagandas nas redes sociais?

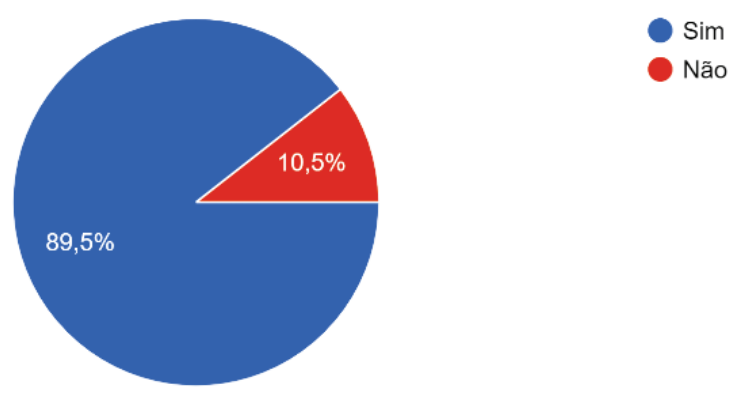

Apesar de mais de 50\% considerarem entre bom e excelente o trabalho de divulgação da FMGR, nessa questão, 89,5\% afirmam que a Faculdade Metropolitana deveria investir mais em propagandas focadas em redes sociais. Uma afirmativa compatível com a visão de Farias (2016), ao afirmar que as estratégias de segmentação de mercado devem, além de seguir a missão e visão das organizações, como dos desdobramentos do seu planejamento estratégico, ser imperativamente disseminados através das redes sociais, que se ajustam e se modernizam constantemente.

Gráfico 3 - Na sua visão, as redes sociais estão trazendo resultado para a Faculdade Metropolitana?

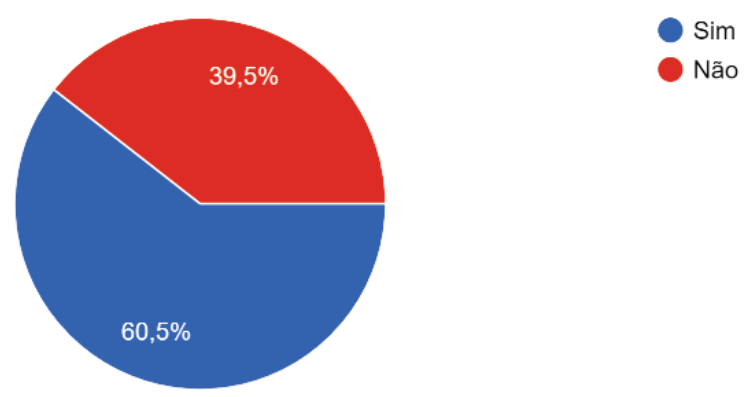

Nessa questão 60,5\% dos alunos de administração da FMGR consideraram as redes sociais como fontes de resultados positivos para a instituição e, num percentual não desprezível, 39,5\% afirmaram que esses resultados não estão ocorrendo via redes sociais. Nessa perspectiva, Kotler et al (2010, p. 109) afirma que "o papel dos consumidores não está limitado a promover as marcas; estende-se também a vendê-las.” Essa venda, no contexto atual de mercado, é fortemente promovida através das redes sociais. 
Gráfico 4 - Como você avalia a comunicação geral da Faculdade com os alunos, através as redes sociais?

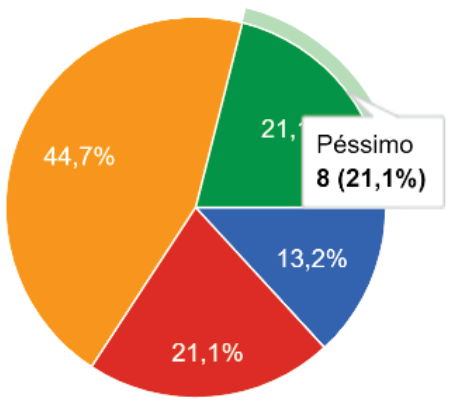

Observamos, de acordo com o gráfico, que $65,8 \%$ classificam de bom a excelente a comunicação que o campo investigativo deste artigo vem realizando junto aos seus alunos, numa comunicação direta pelas redes sociais. Uma perspectiva compatível com a visão de Gómez (2015, p. 25), ao afirmar que "[...] a internet pode estar antecipando uma nova forma de pensar baseada mais nos processos do que nos produtos, na necessidade imperativa de sintetizar a vasta e diversificada morfologia atual da informação.” (GÓMEZ, 2015, p. 25).

Gráfico 5 - Em sua opinião os canais de divulgação e anúncios no Instagram e Facebook sempre lhe mantem informado? Se a alternativa for não, comente.

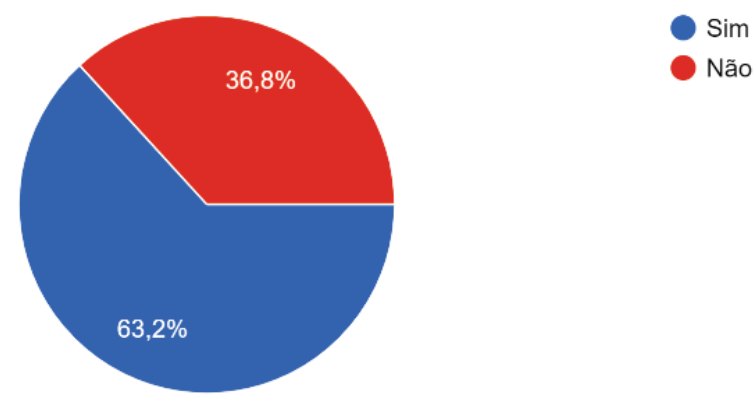

Apenas 36,8\% dos investigados consideram que não estão sendo informados por esses canais de divulgação da Faculdade Metropolitana - Instagram e Facebook. Por outro lado, $63, \%$ afirmaram que sim. Uma perspectiva de realidade bastante positiva e, de certo modo, compatível com as observações de Gummesson (2010), quando destaca a influência que as redes sociais exercem sobre o comportamento de seus usuários, na mesma proporcionalidade em que são, por eles, utilizadas. 
Gráfico 6 - Que benefícios o investimento em marketing digital pode trazer para a Faculdade Metropolitana, na sua concepção?

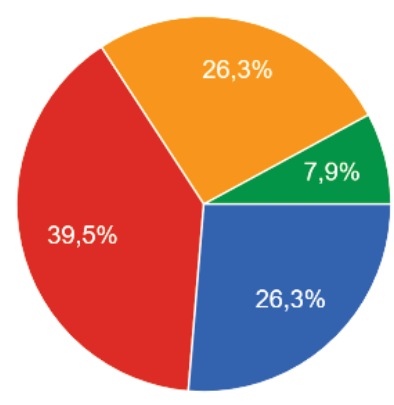

a) Fidelizar alunos;

b) Maior comunicação com alunos;

c) Competir com a concorrência;

d) Uso das redes sociais;

Aqui, 39,5\% dos pesquisados consideram que o maior benefício do marketing digital para a Faculdade Metropolitana é a comunicação com os alunos. Uma perspectiva que vai de encontro com a visão de Farias et al (2015, p. 241) ao afirmar: "pense só nas oportunidades de comunicação, de fidelização e de segmentação. Pense na quantidade de pessoas que jamais teriam acesso a um determinado produto e que, a partir dessa transformação, podem conhecêlo e comprá-lo."

Gráfico 7 - Antes de você entrar na Faculdade você já fez alguma pesquisa nas redes sociais como Instagram ou Facebook sobre cursos oferecidos pela instituição?

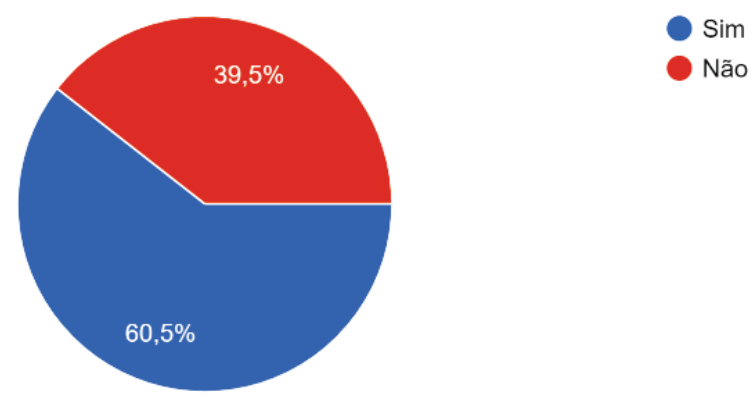

Nessa questão $60,5 \%$ dos entrevistados fizeram alguma pesquisa nas redes sociais sobre cursos oferecidos no mercado. Nesse sentido, afirma Santos (2018, p. 14): “o movimento social é caracterizado pela união de pessoas em torno de um objetivo comum, que compartilham valores políticos e culturais, criando, assim, uma identidade comum ao movimento." 
Gráfico 8 - Você considera importante a Faculdade investir na contratação de um profissional só para se dedicar às ações do marketing digital? Comente sua resposta.

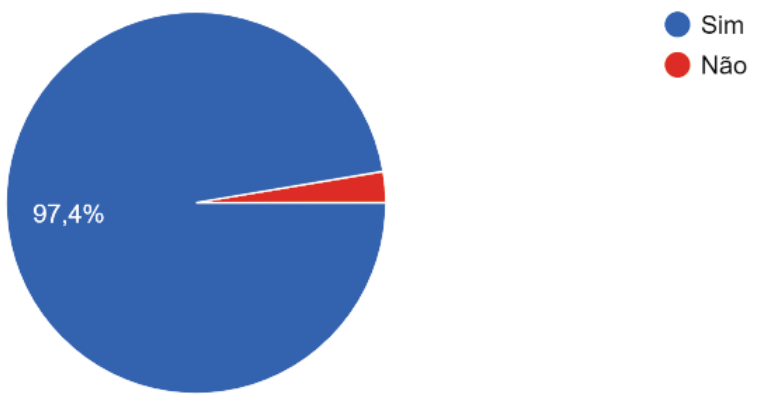

Um expressivo percentual de $97,4 \%$ considera importante a contratação de um profissional especializado na área de marketing digital para a Faculdade Metropolitana. Como bem definiu Kotler et al (2010, p.4): o “[...] marketing precisa segmentar o mercado e desenvolver um produto superior para um mercado-alvo especifico. A regra de ouro segundo a qual 'o cliente é rei' funciona bem para a maior parte das empresas."

\section{CONSIDERAÇÕES FINAIS}

A pesquisa, realizada com alunos do curso de Administração da Faculdade Metropolitana da Grande Recife, durante o primeiro semestre de 2020, revelou que qualquer estratégia ou ação que vise captar e fidelizar clientes deve preceder de objetivos de marketing bem definidos, e seu processo de criação e veiculação nas mídias sociais precisam, necessariamente, estar relacionados com o que se espera alcançar de modo alinhado com os propósitos da instituição em estudo. Outro ponto relevante da pesquisa foi o reconhecimento de que a Faculdade tem se esforçado nas ações do seu marketing digital, mas que esses esforços poderiam ser mais produtivos se fosse contratado um profissional focado nesta atividade, como um digital influencer, por exemplo.

No contexto dos objetivos específicos, merecem destaques, como principais dificuldades de comunicação entre a instituição e seus estudantes, as afirmativas de que a Faculdade não investe adequadamente em propagandas nas redes sociais, de maneira profissionalizada, exatamente pela carência de um profissional especializado nessas ações e que, por isso, muitos $(36,8 \%)$ consideram-se pouco informados pela instituição sobre seus eventos.

No tocante às propostas de melhoria é recomendável que a Faculdade estruture sua área de marketing digital, com a contratação de um digital influencer, além de investir na 
propaganda em redes sociais, de maneira profissionalizada, uma percepção também diagnosticada junto aos alunos que participaram da pesquisa.

\section{REFERÊNCIAS}

FARIAS, Claudio; DUSCHITZ, Caroline; CARVALHO, Gustavo Meneghetti de. Marketing aplicado. Porto Alegre: Bookman, 2015.

. Estratégia de marketing. Porto Alegre: SAGAH, 2016.

GÓMEZ, Á. P. Educação na era digital: a escola educativa. Porto Alegre: Penso, 2015.

GUMMESSON, Evert. Marketing de relacionamento total. 3. ed. Porto Alegre: Bookman, 2010 .

KOTLER, P.; KARTAJAYA, H.; SETIWAN, I. Marketing 4.0: do tradicional ao digital. Rio de Janeiro: Sextante, 2017.

KOTLER, Philip et al. Marketing 3.0: as forças que estão definindo o novo marketing centrado no ser humano. Rio de Janeiro: Elsevier, 2010.

LIMA, A. Como conquistar, fidelizar e recuperar clientes: gestão de relacionamento. São Paulo: Atlas, 2012.

PÉREZ GÓMEZ, Ángel I. Educação na era digital: a escola educativa. Porto Alegre: Penso, 2015.

SANTOS, Ana Paula Fliegner dos et al. Movimentos sociais e mobilização social. Porto Alegre: SAGAH, 2018.

\section{Apêndice A - Modelo de questionário para a pesquisa de campo}

Este instrumento tem por finalidade coletar dados sobre o marketing digital na captação e fidelização de clientes e a realidade dos alunos de administração da Faculdade Metropolitana da Grande Recife, cujo objetivo consiste em verificar a melhor forma de comunicação da instituição com os alunos.

1. O que você acha da divulgação de cursos e eventos da Faculdade Metropolitana?
a) Excelente
b) Bom
c) Regular
d) Péssimo

2. Você acha que a faculdade deveria investir mais em divulgação nas redes sociais? a) $\mathrm{Sim}$ 


\section{b) Não}

3. $\mathrm{Na}$ sua visão, as redes sociais estão trazendo resultados para a Faculdade Metropolitana?
a) $\mathrm{Sim}$
b) Não

4. Como você avalia a comunicação geral da faculdade com os alunos, através das redes sociais?
a) Excelente
b) Bom
c) Regular
d) Péssimo

5. Em sua opinião nos canais de divulgação e anúncios no Instagram e Facebook sempre lhe mantem informado? Se a alternativa for não, comente.
a) $\mathrm{Sim}$
b) Não

6. Qual a sua avaliação sobre os avisos de estágios para os alunos dentro da instituição?
a) Excelente
b) Bom
c) Regular
d) Péssimo

7. Que benefícios o investimento em Marketing Digital pode trazer para a Faculdade, na sua concepção?
a) Fidelizar alunos
b) Maior comunicação com alunos
c) Competir com a concorrência
d) Uso das redes sociais
e) Outro (especifique):

8. Antes de você entrar na faculdade você já fez alguma pesquisa nas redes sociais como Instagram ou Facebook sobre os cursos oferecido pela Metropolitana?
a) $\mathrm{Sim}$
b) Não

9. Você indicaria um amigo para estudar na faculdade? Por qual motivo? Comente sua resposta.
a) $\mathrm{Sim}$
b) Não

10. Como você avalia o desconto oferecido pela faculdade em relação à indicação de amigos? Comente sua resposta.
a) Excelente
b) Bom
c) Regular 
d) Péssimo

11. Você considera importante a faculdade investir na contratação de um profissional só para se dedicar às ações do marketing digital? Comente sua resposta.
a) $\operatorname{Sim}$
b) Não

12. Em uma escala de 0 a 10 quanto você atribui ao marketing digital da Faculdade? E por quê? 